\title{
Buildings Sustainability: The HVAC Contribution
}

\author{
Manuel C. Felgueiras, Rute Santos, Luís M. Fonseca, and Nídia S. Caetano
}

\begin{abstract}
A very important part of the globally produced energy is consumed in buildings, being an important share frequently used in the HVAC systems. These ones are increasing both in performance and in complexity, taking advantage from the use of the recent advances in mechanical and power electronic devices, particularly in the speed variation field. However the improved efficiency only occurs while the HVAC unit is working in the conditions specified by the manufacturer, otherwise the energy consumption raises to values considerably higher than the nominal ones. The adequate maintenance enforces the system to run on its nominal performance and the contrary has undesirable impact both in the performance and in the system expected life time. Therefore, HVAC field maintenance assumes a very important role in the global building sustainability concept.

This work presents some results of an incorrect use of HVAC and the associated electric energy overconsumption that can assume values $50 \%$ higher than those that occur when the installation is operated according to the adequate maintenance plan.
\end{abstract}

Index Terms - Building sustainability, electric energy, HVAC performance.

\section{INTRODUCTION}

Energy is a key issue to sustainable development (that, according to the Bruntland Report [1] is development that meets the needs of the present without compromising the ability of future generations to meet their own needs) indispensable for the many human activities (industry, agriculture, etc.). Traditionally energy systems are based on fossil fuel but its scarcity, irregular distribution, increasing demand and consequent economic implications (e.g. price) and environmental issues such as Climate Change have led to a shift in energy policies. The $40 \%$ of energy-related $\mathrm{CO}_{2}$ emissions is derived from electricity generation [2]. Efficiency increase and use of Renewable Energy Sources (RES) are the main features of today's new energy policies. In modern societies the use of energy is becoming more and more common, and everyday new electric appliances reach the market contributing to raise the energy demand. Also the development of BRIC countries (Brazil, Russia, India and China) contributes to intensify this problem relying in new solutions and/or production paradigms [3].

Major energy consumers include transportation, industry, and buildings. This last is responsible for a demand of over 40\%. Particularly, the HVAC systems represent a significant share of the global energy consumed in the building. More important, if these systems are running out of the conditions

Manuscript received April 20, 2015; revised September 26, 2015. This work was done in the framework of a MSc Thesis in Sustainable Energies, and presented at ISEP, in November 2014.

The authors are with the School of Engineering of the Polytechnic Institute of Porto, ISEP, Portugal (e-mail: mcf@isep.ipp.pt, 1100094@isep.ipp.pt, lmf@isep.ipp.pt, nsc@isep.ipp.pt). clearly indicated by the manufactures the efficiency drops and the energy consumption raises dramatically, with serious consequences both at electric energy consumption and in the expected system life time.

This paper is organized as follows: Energy use; Energy in buildings; HVAC tested systems; Conclusions.

\section{ENERGY ISSUE}

The modern life style has been associated to the use of an important amount of energy, and for many years consuming energy was a synonym of high comfort level and good quality of life. The rapidly growing energy consumption has also raised concerns about the supply, exhaustion of resources and environmental impacts on ozone layer depletion, climatic changes and global warming. To reverse this situation several measures have been proposed. Kyoto protocol was probably the first agreement planned in order to invert this situation, on a global scale that was rapidly followed by actions in all continents. The European Union (EU) approved a first set of targets that will be followed by a second set of new ones in the so called Europe 2020. This is a 10-year plan proposed by the European Commission in March 2010 to revive the European economy. It aims at smart, sustainable, inclusive growth with greater coordination of national and European policy. The policy identifies five headline targets the EU should take to boost growth and employment. One of the five headline goals refers to the previously agreed target to reduce greenhouse gas emissions by at least $20 \%$ compared to 1990 levels or by $30 \%$ if the conditions are right, increase the share of renewable energy in final energy consumption to $20 \%$, and reach a $20 \%$ increase in energy efficiency. The 20-20-20 consists of an emissions and renewables target which is legally binding while the energy saving target is not. The Europe 2020 process which can help promote efficiency and a sustainable growth agenda should not be used to replace national targets and plans, especially at a time when greater transparency, comparability and commitment is required [4].

New trends try to keep the achieved modern quality of life style while lowering the level of energy used. Those includes several procedures that can, in simple ways, be divide in two set of objectives, one from the production side and other on the consumer side:

- The increase on the use of RES;

- The rational use of energy.

The first has as outcome several measures from numerous countries around the world, including EU, to implement and to increase the efficiency and the share of RES in order to contribute to increase the sustainability [5]. The major drawback in the use of RES is its inherent unpredictability that poses huge problems when using an electric energy production paradigm based on the control. In fact, every time one consumer turns on a device (e.g. a light) the demand 
increase and the electric service provider should dynamically and in real-time balance the demand with the production. In order to do that the use of primary controllable energy sources is crucial. Except for the hydro-storage energy, all controllable energy sources are fossil derived.

In this scenario, the use of RES energy such as the wind-based brings serial constrains resulting from its lack of controllability. As consequence, typically are only injected in the grid power values from the wind-based energy lower than $25 \%$ of the total power installed.

This percentage remains approximately constant even when higher values of wind-based energy are available from wind-energy farms. In this case we have available energy that is not injected in the grid mainly because of the growing risks associated with the continuity of service. The higher was the over percentage, the more often was the associated wind-cuts i.e. the refuse in the use of wind-based energy. The solution for this issue includes the use of a different electric energy production paradigm that will take advantage of the use of Information and Communications Technology (ICT). However, all that issues and specifically the migration to a different energy paradigm able to accommodate more, and virtually unlimited, amount of electric energy, are currently under development and consequently not feasible at short-term.

The second includes several aspects including the device/equipment performance, the user behaviors, the equipment use conditions, etc. Efforts to increase the efficiency are a matter considered transversely to all industrial and household appliances. The most perceptible face of this modification is the use of Light Emitting Diode (LED) applied in lighting, TVs, Personal Computers (PC), and a panoply of new and more efficient appliance devices. In general, we can perceive that performance increase is often associated with a complexity raise. As an example, in the past traditional power supply generically used in all electronic devices were based in the topology of the so called Linear Power Supply, in which the first block was a power transformer used to step-down the $110 \mathrm{~V}$ or $230 \mathrm{~V}$ voltages from electric power grid to voltages compatible with the used electronic, (e.g. 5V) typically used in digital circuits, such as the mobile phone chargers. As attributes, those power supply devices were heavy (due to the presence of the transformer) and presented a global efficiency around 50\%. Gradually those equipment have been replaced by a new generation of power supply devices based in the topology Switch-mode Power Supply. These are much lighter, present considerably higher level of complexity but also a global performance never lower than $90 \%$.

Generically we can perceive that the electronic and the ITC technologies arenas have a raising importance in the modern equipment. In fact they frequently are not essential to the basic function of the equipment but are crucial if high performance and low consumption is wanted. As an example, if we compare modern cars with their ancestral models the first present higher efficiency only possible to obtain due to the use of massive electronic sensors and control systems. The same conclusion is obtained when comparing new and older light bulbs: higher efficiency but also higher complexity. However, the introduction of electronics carries also disadvantages as traditional linear loads are often transformed in non-linear ones. This has negative impact on the electric grid because increases the Total Harmonic Distortion (THD) and for so, lowers the electric quality of energy [6].

In general, electronics and ICT have special role in systems, increasing their efficiency but also complexity. The field maintenance is essential to maintain those systems in the nominal conditions. The complexity of systems raises and for so, technicians with higher skills level are needed.

\section{ENERGY IN BUILDINGS}

Buildings are crucial to a sustainable future as their design, construction, operation, and the activities in buildings are substantial contributors to energy-related sustainability challenges. Consequently, reducing energy demand in buildings can play one of the most important roles in solving these challenges. In fact buildings activities are responsible for approximately $31 \%$ of global final energy demand, approximately one-third of energy-related $\mathrm{CO}_{2}$ emissions, approximately two-thirds of halocarbon, and approximately $25-33 \%$ of black carbon emissions. Also energy-related problems affecting human health and productivity take place in buildings, including mortality and morbidity due to poor indoor air quality or inadequate indoor temperatures. Therefore, improving buildings and their equipment offers one of the entry points to addressing these challenges [7].

The global energy demand has been usually grouped in a few main areas such as industry, transports and other that include the energy consumed in buildings. The share of energy used in each area is continuously changing but we can denote that the share of energy used in buildings is increasing. In fact, this last has assumed so high importance that is currently identified as one independent share. Energy efficiency in buildings is today a prime objective of the European Commission that has launched the Greenbuilding programme, aiming at raising awareness and triggering additional investments in energy efficiency and renewable energy among owners in new and refurbished non-residential buildings. As a result of the participation of more than 650 buildings that have included better insulation, more efficient heating, cooling or lighting devices, control systems and energy management, the programme is saving more than 514 GWh per year [8]. From that, an important part is due to the HVAC systems. With the implementation of the Ecodesign Directive, it is expected that by the end of the year 2020 about $11 \mathrm{TWh}$ of energy can be saved each year, only due to the use of more efficient HVAC systems [8].

Among the building services the growth in HVAC energy systems use is important, achieving $50 \%$ of the total building energy consumption.

In the EU the total amount of energy produced is mainly consumed by three sectors as represented in Fig. 1 [9].

In the U.S. every year, nearly half $(47.6 \%)$ of all energy produced is consumed by the Building Sector - about the same amount of energy consumed by both transportation $(28.1 \%)$ and industry (24.4\%) combined sectors [9]. As shown the share of energy consumed in buildings represents about 40\%. Accordingly [9] the global contribution from buildings towards energy consumption, both residential and commercial has progressively increased reaching values 
between $20 \%$ and $40 \%$ in developed countries, and has exceeded the other major sectors: the industrial and transportation. In terms of primary energy consumption, buildings represent around $40 \%$ in most IEA countries. The U.S. Energy Information Administration (EIA) now reports that, in coming years, Building sector energy consumption will grow faster than that of industry and transportation. Between 2012 and 2030, the EIA reports, total Building sector energy consumption will increase by 4.74 Quadrillion Btu (QBtu). Industry will grow by 3.33 QBtu and Transportation is expected to decrease by $0.37 \mathrm{QBtu}$. To put these projections into perspective, $1 \mathrm{QBtu}$ is equal to the delivered energy of thirty-seven 1000-MW nuclear power plants, or 235 coal-fired power plants at 200-MW each [10], [11].

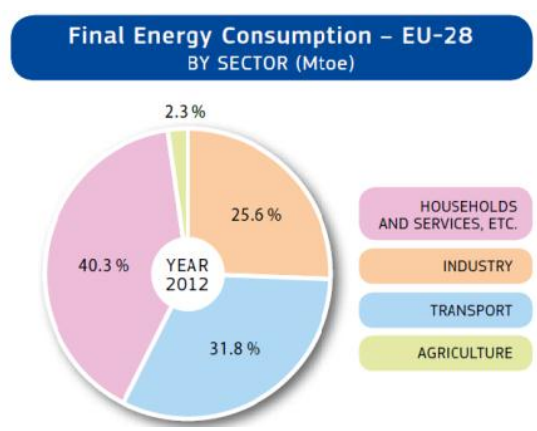

Fig. 1. Share of the energy consumed by household and services in EU.

For counteracting this state it is necessary to use new technologies and techniques that point the ideal situation, i.e., an energetically self-sufficient building. This scenario is no longer as far as it has been in the near past. The so called Zero Energy Building (ZEB) [12], [13] is under strong research at present. This new buildings design involves assessing how the building will integrate into its surrounding environment. (e.g., if a building is near a mountain, this will determine where the windows are placed to ensure maximum exposure to sunlight in cold climate). The process also involves working on the design and overall shell (roofs, walls, windows) of the building. The last step is to use the most efficient appliances and equipment [14].

One important step was done by the presentation of the Energy Performance of Buildings (EPBD) Directive (2002 and recast in 2010). The EPBD addresses new buildings and those undergoing major renovation (which amounts to $40 \%$ of the EU energy use, $36 \% \mathrm{CO}_{2}$ emissions). Both its transposition and implementation have been slow. Its recast in 2009 has strengthened the Directive but less than hoped, in particular regarding to existing buildings, financing and urgency of deadlines [15]. The other important step refers to the adequate use of building equipment's in which the appropriate use of HVAC represents a significant portion of energy used in buildings. Several projects intend to know in what conditions HVAC are operating and how they can be more efficient. The main idea consists on inspection of HVAC systems through continuous monitoring in order to later compare results and perform benchmarking [16].

In the next section we present comparative results of poor and appropriate use of HVAC systems.

\section{HVAC STUDIED}

The main objective of the HVAC is to (i) renew the air inside (e.g. room, store, office. etc.) and (ii) control air temperature. Depending on the season, the system should be able to remove or introduce heat.

\section{A. HVAC Principle}

The HVAC system principle is presented in Fig. 2. The system includes an air fan, an air cooler element, an air heater element, air filter and additional elements such silencer elements and pipelines. The air intake is a mixture of the air input from the inside of the room and of the new air coming from the outside of the room. This air mixture crosses the filter and then the cooler element, the heater element, the fan and finally is introduced in the room. The use of new air is necessary to satisfy ventilation requirements whereas the recirculated air is used to obtain performance benefits. Major energy consumers include the chiller that supplies the cooler element, the boiler that supplies the heater element and the fan that is responsible for flowing all the air mass involved in the process.

\section{B. Tested HVACs}

There were tested three different equipment, with very different features (e.g. size, power, etc.) and designed for different installation needs [17]. As a common characteristic those equipment were used to service a single room.

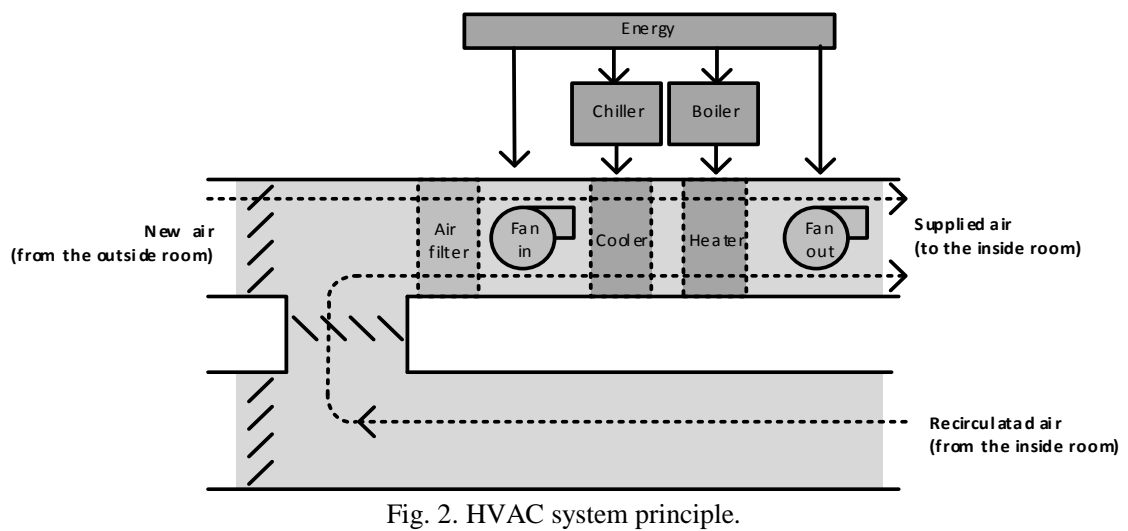

\section{The Test Method}

The test methodology intends to demonstrate the impact of an adequate maintenance in HVAC equipment, particularly the filter. The comparative test aims to demonstrate in what way the filter changes HVAC behavior and how important are the deviations from the nominal conditions when the 
system runs out from the reference manufacturer requirements. The methodology used was based in the measurement of a set of properties before and after the filter replacement action is all equipment. The selected set of properties is as follows:

- Temperature in the recycled air input

- System response time

- New air flowrate

- Recirculated air flowrate

- Supplied air flowrate

- Current absorbed by motor 1

- Current absorbed by motor 2

The test method is based on the time needed to make the room internal air temperature drop $1^{\circ} \mathrm{C}$. To perform this operation it is necessary to measure the temperature in the recycled air input and the time associated to the specified temperature decrease.

The measured air flow rate in the three input/output intends to compare the impact before/after the filter replacement.

The filter acts as an air flow obstruction and for so this opposition rises as consequence of the filter clogging. Therefore it was expected the resistant torque to rise as well as the associated current in the electric motors fan. Consequently, it was considered important to measure the three currents in the AC motors.

\section{Test Results and Discussion}

As explained before, the proposed methodology was applied to three HVAC systems and the results are presented in Table I.

TABLE I: CHARACTERIZATION OF HVAC SYSTEMS TESTED

\begin{tabular}{|c|c|c|c|c|c|c|}
\hline \multirow[b]{4}{*}{$\begin{array}{l}\text { New air flowrate } \\
\left(\mathrm{m}^{3} / \mathrm{h}\right)\end{array}$} & \multicolumn{6}{|c|}{ HVAC system under test } \\
\hline & \multicolumn{2}{|c|}{$\# 1$} & \multicolumn{2}{|c|}{$\# 2$} & \multicolumn{2}{|c|}{ \#3 } \\
\hline & Before & After & Before & After & Before & After \\
\hline & 5100 & 11000 & 2650 & 4000 & 19500 & 24400 \\
\hline $\begin{array}{l}\text { Supplied air flowrate } \\
\left(\mathrm{m}^{3} / \mathrm{h}\right)\end{array}$ & 5200 & 12000 & 2700 & 4100 & 19500 & 24400 \\
\hline $\begin{array}{l}\text { Recirculated air } \\
\text { flowrate }\left(\mathrm{m}^{3} / \mathrm{h}\right)\end{array}$ & 4900 & 9000 & 2400 & 3800 & 18000 & 23000 \\
\hline $\begin{array}{l}\text { Supplied air } \\
\text { temperature }\left({ }^{\circ} \mathrm{C}\right)\end{array}$ & 21.8 & 20.3 & 20.0 & 21.0 & 25.0 & 24.0 \\
\hline $\begin{array}{l}\text { New air temperature } \\
\left({ }^{\circ} \mathrm{C}\right)\end{array}$ & 33.0 & 32.5 & 28.0 & 27.0 & 28.0 & 27.0 \\
\hline $\begin{array}{l}\text { Recirculated air } \\
\text { temperature }\left({ }^{\circ} \mathrm{C}\right)\end{array}$ & 23.5 & 23.5 & 21.0 & 21.0 & 22.0 & 21.0 \\
\hline $\begin{array}{l}\text { Recirculated air set } \\
\text { point }\left({ }^{\circ} \mathrm{C}\right)\end{array}$ & 22.5 & 22.5 & 20.0 & 20.0 & 21.0 & 20.0 \\
\hline $\begin{array}{l}\text { System response time } \\
\text { (min) }\end{array}$ & 4 & 1.45 & 3 & 1 & 18 & 11 \\
\hline $\begin{array}{l}\text { Motor-in [RST } \\
\text { currents] (A) }\end{array}$ & 5.30 & 5.40 & 1.5 & 1.5 & 12.7 & 12.9 \\
\hline $\begin{array}{l}\text { Motor-out [RST } \\
\text { currents] (A) }\end{array}$ & 2.80 & 2.90 & 0.8 & 0.8 & 12.0 & 12.2 \\
\hline $\begin{array}{l}\text { Increased supplied air } \\
\text { flowrate }(\%)\end{array}$ & 130 & & 52 & & 25 & \\
\hline $\begin{array}{l}\text { Increased recirculated } \\
\text { air flowrate }(\%)\end{array}$ & 84 & & 58 & & 28 & \\
\hline $\begin{array}{l}\text { Decreased syst. } \\
\text { response time }(\%)\end{array}$ & 36 & & 33 & & 61 & \\
\hline
\end{tabular}

Table I presents some data collected directly from the HVAC system under test, whereas the lower part shows some calculations.

Let us examine the first example, the HVAC \#1. As said, the system set point corresponded to the recirculated air temperature decreased by one degree. The recirculated air temperature was $23.5^{\circ} \mathrm{C}$ and for so the correspondent recirculated air set point should be $22.5^{\circ} \mathrm{C}$.

After the maintenance operation, the increase supplied air flowrate variation obtained was about $130 \%$ whereas increased recirculated air flowrate was $84 \%$. The decreased system response time was only $36 \%$, i.e. the new response time is only $36 \%$ of the previous. The fan motors currents remain approximately constant and for so the corresponding input power. We did not use electric energy meters during the tests but the electric energy is estimated by:

$$
E=P \cdot t
$$

where $P$ represents the electric power (i.e. W), t represents the time interval (e.g. $h=$ hour) and $E$ represents the electric energy (e.g. kW/h). In the analyzed example (HVAC \#1) the motors power remain constant while the new response time is only $36 \%$ of the initial time. It is easy to calculate that we obtain $64 \%$ of energy savings for the fan motors.

Therefore, the savings are directly linked to the decreased system response time. Analyzing all the remaining tested examples we can perceive similar figures although results are dependent of the clogging filter level. In all the systems tested, the relative energy saved is significant but the absolute energy savings depends on the fan power that is linked to dimension and also to the global power system.

These results are consistent with those obtained by Balaras et al. [18], who concluded that adequate maintenance can contribute to better quality of the indoor air exchange, as well as to better control on indoor thermal conditions, therefore with lower energy consumption.

\section{CONCLUSION}

The HVAC systems are responsible for a very important share of the globally consumed energy. If they work under the conditions indicated by the manufacturers the energy consumed in under the nominal conditions. However, the absence or inadequate maintenance makes the HVAC system run out of those conditions. The energy consumption raises and the expected equipment life-time can be significantly reduced. Both situations are against the sustainability guidelines and for so should be avoided.

These systems include several energy consuming parts. This paper presented some data related to the importance of adequate HVAC maintenance in field and the corresponding electric energy savings for the HVAC electric fan due to proper maintenance. As seen the inadequate maintenance (that includes filter replacement) has a high importance and can be responsible for the raising in energy consumption of $275 \%$. This study does not include the energy in the boiler and chiller.

Improvements and new directions of this work will include the development of a new system that automatically displays the need for filter replacement.

\section{REFERENCES}

[1] World Commission on Environment and Development, Our Common Future, Oxford: Oxford University Press, 1987, p. 27

[2] International Energy Agency. (February 2015). [Online]. Available: http://www.iea.org/topics/electricity/ 
[3] C. Felgueiras and F. Martins, "RES-Managing the unpredictability," in Proc. the $4^{\text {th }}$ International Conference on Renewable Energy Sources, Tatranské Matliare, High Tatras, Slovak Republic, 2013, pp. 179-182.

[4] European Environmental Bureau. (2015). Current EU Energy Saving Legislation and other Instruments. [Online]. Available: file:///C:/Users/Calos\%20Felgueiras/Downloads/FACT\%20SHEET\% 202\%20-\%20Current\%20EU\%20Energy\%20Legislation\%20and\%20 other\%20instruments\%20(10).pdf

[5] C. Felgueiras and F. Martins, "RES-Electricity in Europe - Policy and support instruments," in Proc. the $4^{\text {th }}$ International Conference on Renewable Energy Sources, Tatranské Matliare, High Tatras, Slovak Republic, 2013, pp. 135-139.

[6] C. A. Petry, J. Moia, F. S. Pacheco, R. A. Gustavo, and M. C. Felgueiras, "Streamlining power electronics teaching,"XI Congreso de Tecnologías, Aprendizage y Enseñanza de la Electrónica (TAEE), Bilbao, España, 2014.

[7] D. Ürge-Vorsatz, "Energy end-use: Buildings," Global Energy Assessment - Toward a Sustainable Future, Cambridge, UK Cambridge University Press, 2012, ch. 10, pp. 649-760.

[8] Science for Energy. Joint Research Centre, Scientific and Technical Research Series Luxembourg: Publications Office of the European Union. [Online]. Available: http://Dx.Doi.Org/10.2788/88328

[9] European Commission, EU Energy and Transport in Figures Statistical Pocket Book, 2014.

[10] U.S. Energy Information Administration. (2014). [Online]. Available: http://www.iea.org/

[11] L. Pérez-Lombarda, J. Ortiz, and C. Pout, "A review on buildings energy consumption information," Energy and Buildings, vol. 40, no. 3 pp. 394-398, 2008.

[12] P. Hernandeza and P. Kennyb, "From net energy to zero energy buildings: Defining life cycle zero energy buildings (LC-ZEB)," Energy and Buildings, vol. 42, no. 6, pp. 815-821, 2010.

[13] A. J. Marszala, P. Heiselberga, J. S. Bourrelleb, E. Musallc, K. Vossc, I Sartorid, and A. Napolitanoe, "Zero energy building - A review of definitions and calculation methodologies," Energy and Buildings, vol. 43, no. 4, pp. 971-979, April 2011

[14] G. Li, Z. G. Huang, and H. B. Zhou, "The study on how to optimize energy saving technology on central air-conditioning for existing buildings," Journal of Clean Energy Technologies, vol. 1, no. 4, pp. 339-341, 2013.

[15] S. Schimschar, S. Surmeli, and A. Hermelink, "Guidance document for national plans for increasing the number of nearly zeroenergy buildings," European Environmental Bureau, 2013.

[16] Inspection of HVAC Systems through Continuous Monitoring and Benchmarking. (2011-2014). [Online]. Available: http://www.iservcmb.info/

[17] R. C. C. Santos, "Contribution of the building technical maintenance to sustainability," MSc dissertation on sustainable energies, ISEP, School of Engineering, Polytechnic Institute of Porto, 2014.

[18] C. A. Balaras, E. Dascalaki, and A. Gaglia, "HVAC and indoor thermal conditions in hospital operating rooms," Energy and Buildings, vol. 39, no. 4. pp. 454-470, 2008.

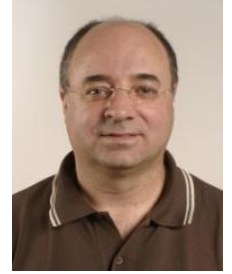

Manuel C. Felgueiras received the B.S. and Ph.D degrees in electrical and computer engineering from the Faculty of Engineering, University of Porto, Porto, Portugal, in 1987 and 2008, respectively. He started his activity in 1994 as an assistant professor and later on as an adjunct professor and researcher with the Department of Electrical Engineering, School of Engineering (ISEP), Polytechnic Institute of Porto (IPP), Porto, Portugal.

His research interests at CIETI include design for debug and test of mixed-signals, remote experimentation in e-learning and renewable energy source.

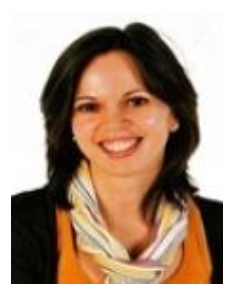

Rute Santos obtained her B.S. degree in electrical engineering: energy systems from the School of Engineering, Polytechnic Institute of Coimbra in 1999 and MSc degree in sustainable energies from ISEP, IPP, in 2014, respectively. She started her professional activity in 2000 in the paper pulping industry, as the chief in charge of the electricity and instrumentation maintenance. In 2005, she started the activity as maintenance contracts officer in the field of both buildings in industrial environment and in the service sector.

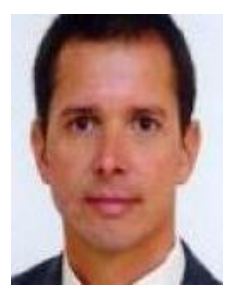

Luís M. Fonseca is an adjunct professor at ISEP-IPP, School of Engineering Polytechnic of Porto since 1989. He has a $\mathrm{PhD}$ degree in management from ISCTE-IUL, Lisbon University Institute in 2012 and was an electrical engineer in FEUP, the Faculty of Engineering of the University of Porto in 1982. He is an ASQ fellow with 15 years' experience in systems certification business in addition with senior manager experience.

His research interests include quality, management, sustainability, social responsibility and industrial engineering and management.

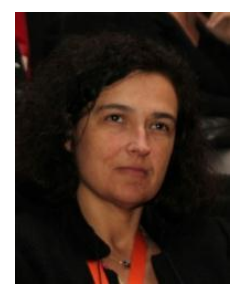

Nídia S. Caetano received her B.S. and Ph.D degrees in chemical engineering from the Faculty of Engineering of the University of Porto (FEUP), Porto, Portugal, in 1987 and 1996, respectively. She started the teaching activity in 1992 as an assistant professor and today is a coordinator professor with the CED, of ISEP/IPP. From March 2013, she has been the director of the master course on Sustainable Energies of ISEP/IPP, in the MED.

Her research interests include biofuels (waste to energy: biodiesel, bioethanol, biogas, combustion) either from waste biomass, oil or microalgae; efficient use of solar energy for microalgae production; valorization of solid waste and wastewater treatment, always using a sustainability based approach 


\section{Energy Policy}


